\title{
Megaloblastic Anemia and Other Causes of Macrocytosis
}

\author{
Florence Aslinia, MD; Joseph J. Mazza, MD, MACP; and Steven H. Yale, MD, FACP
}

Keywords:

Anemia

Macrocytosis

Megaloblastic
Reprint Requests:

Steven H. Yale, MD

Department of Internal Medicine

Marshfield Clinic

1000 North Oak Avenue

Marshfield, WI 54449

Telephone: 715-387-5436

Fax: 715-389-3808

Email:yale.steven@mcrf.mfldclin.edu
Received: December 12, 2005

Revised: May II, 2006

Accepted: June 19, 2006 he term macrocytosis refers to a blood condition in which red blood cells (RBC) are larger than normal. Macrocytosis is reported in terms of mean corpuscular volume (MCV). Normal MCV values range from 80 to 100 femtoliters (fl) and vary by age and reference laboratory. ${ }^{1} \mathrm{MCV}$ is calculated according to the following formula:

$$
\operatorname{MCV}(\mathrm{fl})=[\text { Hematocrit }(\text { percent }) \times 10] /\left[\mathrm{RBC} \text { count }\left(10^{6} / \mu \mathrm{L}\right)\right]
$$

Macrocytosis can be identified by reviewing peripheral blood smears and/or by automated RBC indices. The peripheral blood smear is more sensitive than RBC indices for identifying early macrocytic changes because the MCV represents the mean of the distribution curve and is insensitive to the presence of small numbers of macrocytes. ${ }^{2}$ However, compared to the peripheral blood smear, MCV may underestimate macrocytosis in over $30 \%$ of cases. $^{3}$

Although determination of the MCV by automated blood cell counter is rarely inaccurate, hyperglycemia, marked leukocytosis and cold agglutinins may result in false elevations of the $\mathrm{MCV}^{4-6}$ Moreover, partial occlusion of the instrument aperture and/or leaving the blood sample at room temperature for several hours may also result in false elevations of the MCV value.

\section{Clinical Significance}

Macrocytosis is a relatively common finding in the era of automated blood cell counters, with prevalence estimates ranging from $1.7 \%$ to $3.6 \% .3,7,8$ Its significance tends to be underestimated by physicians, since about $60 \%$ of patients present without associated anemia, ${ }^{8}$ unless there are other accompanying abnormalities noted.

No complications arise from macrocytosis itself as an isolated finding. However, its identification can provide important information regarding the presence of an underlying disease state. Thus, in the appropriate clinical setting, MCV values above the upper limit of normal or those that differ significantly from the patient's baseline values may require further clinical and laboratory assessment to determine the underlying cause of the macrocytosis. ${ }^{9}$ 


\section{Macrocytosis Without Anemia}

Large circulating erythrocytes are not always associated with a pathologic process or condition. In fact, RBCs of newborns and infants tend to be larger (mean $\mathrm{MCV}=108 \mathrm{fl}$ ) than normal adult RBCs, ${ }^{10,11}$ and large erythrocytes can be seen during pregnancy in the absence of an obvious etiology. Macrocytosis without anemia may be a normal variant and is only noted as a result of repeated peripheral RBC indices in the absence of any known or existing clinical problems. In some instances this variation from normal can be found in other family members, which suggests a genetic predisposition, and requires no therapeutic intervention or further investigation. ${ }^{12,13}$

\section{Macrocytosis With Associated Anemia}

Macrocytic anemia describes an anemic state characterized by the presence of abnormally large RBCs in the peripheral blood. This abnormality is usually recognized by the automated blood cell counter and confirmed on review of the peripheral blood smear. The cause of macrocytic anemia may be due to a variety of illnesses and demands further clinical and laboratory assessment. Macrocytic anemia can usually be divided into two categories, megaloblastic and nonmegaloblastic, based on the examination of the bone marrow. This categorization is important and frequently aids in determining the etiology of the anemia. Additionally, a careful review of the peripheral blood smear noting the morphology of the RBCs, as well as the other cellular elements and features on the smear, can provide important clues as to the etiology of the anemia.

The spectrum of etiologies associated with macrocytic anemia includes nutritional deficiencies (e.g., vitamin B12 and folate), drugs (table 1), primary bone marrow disorders (e.g., myelodysplasia and leukemia) and other chronic illnesses (table 2). Macrocytosis due to vitamin B12 or folate deficiency is a direct result of ineffective or dysplastic erythropoiesis. These important vitamins and cofactors are required for normal maturation of all cells. Marrow erythroblasts are no exception. When either of these two factors is deficient, RBC proliferation and maturation result in large erythroblasts with nuclear/cytoplasmic asynchrony. These abnormalities are caused by a defect in DNA synthesis that interferes with cellular proliferation and maturation. RNA synthesis and cytoplasmic components remain relatively unaffected. The marrow is hypercellular with all forms of the myeloid cell line being increased and erythroid elements being dominant on the marrow aspirate smear preparations. The erythroblasts become large, oval shaped and contain a characteristic immature, lacy nucleus. These bone marrow features are called "megaloblastic" and are highly suspicious of a vitamin B12 or folate deficiency. Megaloblastoid (megaloblastic-like) abnormalities of the marrow are frequently seen in other hematologic disorders not associated with vitamin B12 or folate deficiency, (e.g., myelodysplasia and leukemia) and a careful examination of the bone marrow is necessary to make this distinction.
Table 1. Drugs that may induce macrocytosis.

\begin{tabular}{cc}
\hline Chemotherapeutic agents & Antimicrobials \\
Cyclophosphamide & Pyrimethamine \\
Hydroxyurea & Sulfamethoxazole \\
Methotrexate & Trimethoprim \\
Azathioprine & Valacyclovir \\
Mercaptopurine & \\
Cladribine & Diuretics \\
Cytosine arabinoside & Triamterene \\
5-Fluouracil & \\
& \\
Antiretroviral & Anticonvulsant agents \\
Zidovudine & Phenytoin \\
Stavudine & Primidone \\
& Valproic acid \\
Hypoglycemic & Anti-inflammatory \\
Metformin & Sulfasalazine \\
& \\
& Other \\
& Nitrous oxide \\
\hline
\end{tabular}

Macrocytosis is frequently linked to alcoholism, with or without liver disease. In fact, it is purported to be one of the most common causes of nonmegaloblastic macrocytosis. ${ }^{9}$

\section{Investigation of Macrocytosis}

The evaluation of the patient with macrocytosis requires a systemic approach. It should begin with a comprehensive history and physical examination followed by appropriate laboratory studies that include a complete blood count, a peripheral blood smear and reticulocyte count. In some cases, a bone marrow examination may be necessary.

Determining the underlying cause of the macrocytosis can be particularly challenging when thalassemia trait or iron deficiency or other nutritional deficiencies coexist with a vitamin B12 or folate deficiency. In these instances the

Table 2. Common pathologic causes of macrocytosis.

Drugs

Alcoholism

Reticulocytosis

Nonalcoholic and alcoholic liver disease

Hypothyroidism

Vitamin B12 deficiency

Folate deficiency

Multiple myeloma

Myelodysplastic syndromes

Aplastic anemia

Acute leukemia 

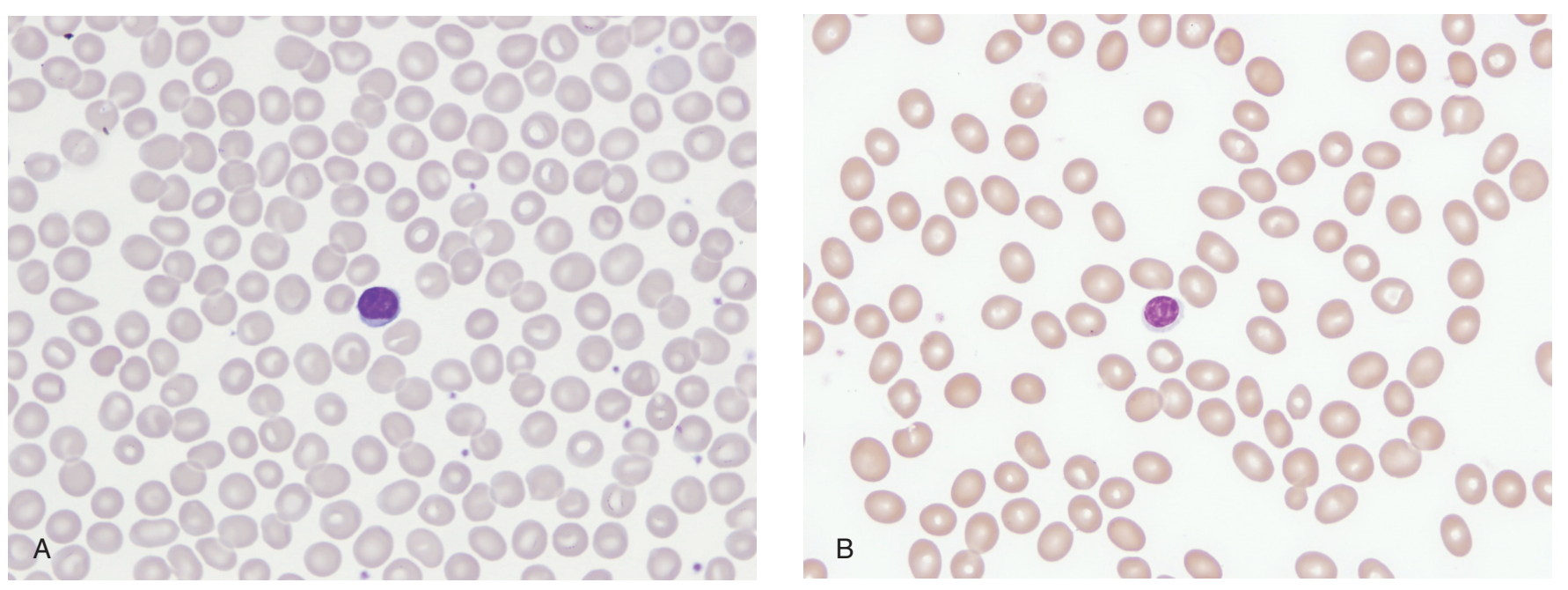

Figure 1. (A) Marked macro-ovalocytosis (MCV $134 \mathrm{fl}$ ) in the peripheral blood smear of a patient with vitamin B12 deficiency. (B) Predominantly round macrocytes $(\mathrm{MCV}=114 \mathrm{fl})$, some targeted, in the peripheral blood smear of a patient with liver disease.

peripheral blood smear may show a mixed population of microcytic and macrocytic RBCs with an elevated distribution width. In cases of macrocytosis related to alcoholism the elevated MCV may be due to the direct effect of the alcohol, liver disease and/or folate deficiency.

\section{History and Physical Examination}

Evaluation of macrocytosis begins with a complete history and physical examination to search for signs and symptoms related to an acute or chronic underlying illness that may be obvious or occult in nature. Medications such as antimicrobial, chemotherapeutic and anticonvulsant agents can account for a significant number of cases of macrocytosis, with or without anemia (table 1), emphasizing the importance of taking a careful inventory of the patient's medications. In some instances, macrocytosis may serve as a surrogate marker indicating the patient's compliance in taking his/her medications. ${ }^{14-17}$ A similar degree of importance applies to the patient's dietary history and his/her use of alcohol.

\section{Peripheral Blood Smear}

A review of the peripheral smear is imperative in determining the etiology of macrocytosis. The presence of macro-ovalocytes having an MCV $>115 \mathrm{fl}$, anisocytosis, poikilocytosis and hypersegmented neutrophils suggests a megaloblastic disorder associated with a nutritional deficiency, i.e., vitamin B12 or folate deficiency. Round macrocytes are commonly seen in a variety of chronic illnesses, and round target-appearing macrocytes are characteristic of liver disease such as hepatitis, obstructive jaundice, and acute and chronic alcoholism with liver disease (figure 1). For patients who present with disordered immaturity, hypogranulated or hyposegmented neutrophils, and cytopenias, a bone marrow examination is necessary to rule out or confirm a primary bone marrow disorder such as a myelodysplastic syndrome or leukemia.

\section{Reticulocyte Count}

A reticulocyte count should be obtained if there is evidence of hemolysis on the peripheral smear, i.e., increased polychromasia, nucleated RBCs, spherocytes or schistocytes. ${ }^{18}$ The presence of increased polychromasia of the macrocytes on the peripheral smear and a reticulocyte count of $>10 \%$ should raise suspicion of hemolysis or an acute bleed. These large polychromatophilic erythrocytes noted on the peripheral smear represent reticulocytes, immature RBCs that are larger than mature RBCs, and are indicative of increased erythropoiesis or $\mathrm{RBC}$ production and, if present in increased number, can raise the MCV. Additionally, the reticulocyte maturation parameters performed on the peripheral blood may also be helpful to differentiate megaloblastic from nonmegaloblastic causes of the macrocytosis. ${ }^{19}$ An elevated reticulocyte maturation value is more suggestive of a megaloblastic rather than a non-megaloblastic anemia.

\section{Bone Marrow Examination}

Macrocytosis associated with a megaloblastic marrow is usually accompanied by anemia due to ineffective erythropoiesis. The bone marrow is hypercellular, showing evidence of abnormal proliferation and maturation of multiple myeloid cell lines. These abnormalities are most evident in the erythroid precursors with large megaloblastic erythroblasts present in increased numbers throughout the marrow. Similar morphologic abnormalities can be seen in the other myeloid elements, e.g., large or giant metamyelocytes and other granulocytic precursors. This ineffective erythropoiesis is accompanied by intramedullary hemolysis causing an elevated lactate dehydrogenase and indirect bilirubin in the serum..$^{20-22}$ However, the reticulocyte count is low due to the abnormal maturation process. More severe degrees of abnormal proliferation and maturation are seen with myelodysplasia and myeloid leukemias. It is imperative that a hematologist or hematopathologist examine the marrow in order to appreciate these important, subtle, hematopoietic abnormalities. Patients with macrocytosis who are not anemic and have no other abnormalities noted on the peripheral blood smear do not usually need a bone marrow examination. 
Investigation of Vitamin B I 2 and Folate Deficiencies Macrocytosis is the earliest abnormality seen in complete blood counts of patients with folate or vitamin B12 deficiency. In patients with elevated MCV values, laboratory tests for vitamin B12 and folate deficiencies are routinely ordered by physicians, although these tests are limited by their low sensitivity and specificity. Like the RBC MCV, the lower limits of normal for vitamin B12 levels are not well defined. ${ }^{23}$

\section{Serum B12 Levels}

Vitamin B12 levels may be reported as normal or elevated in myeloproliferative disorders, liver disease, congenital transcobalamin II deficiency, intestinal bacterial overgrowth and antecedent administration of vitamin B12.24 Moreover, there are reports of falsely low vitamin B12 levels with folate deficiency, pregnancy, use of oral contraceptives, congenital deficiency of serum haptocorrins and multiple myeloma. ${ }^{24}$ The prevalence of vitamin B12 deficiency among the elderly ranges from $1.5 \%$ to $4.6 \%{ }^{25}$ and was reported to be as high as $15 \%$ in the population over the age of 60 years. ${ }^{26}$ The deficiency in many cases is associated with gastric achlorhydria, resulting in decreased synthesis and availability of intrinsic factor, a necessary binding protein that facilitates vitamin B12 absorption in the ileum. This constellation of events eventually leads to pernicious anemia and requires prompt intervention with exogenous vitamin B12 preparations. The diagnosis of pernicious anemia can be confirmed by identifying and measuring intrinsic antibody levels in the serum. Parietal cell antibodies, although not specific, are also commonly present. However, these tests are expensive and not always available to the practicing clinician.

\section{Serum Folate Levels}

Folic acid deficiency in the United States is extremely rare because of the fortification of foods. ${ }^{27}$ Although tissue stores may be normal, serum folate levels can decrease within a few days of dietary folate restriction. ${ }^{24}$ Thus, patients should fast prior to testing for serum folate levels, as serum folate levels increase with feeding. Because of the high concentration of folate within the RBC, mild degrees of hemolysis can falsely elevate serum folate levels. ${ }^{24}$ Pregnancy, certain anticonvulsant drugs, and alcohol intake may also cause a decrease in serum levels despite adequate tissue stores. Serum folate levels tend to be increased in patients with vitamin B12 deficiency, presumably because of impairment of the methionine synthase pathway and accumulation of methyltetrahydrofolate, the principal form of folate in the serum. ${ }^{28-30}$

\section{RBC Folate}

Because of the limitations of measuring serum folate, RBC folate levels have been advocated as a more reliable source of measuring tissue stores of folate. $\mathrm{RBC}$ folate levels remain constant throughout the lifespan of the cell and are not affected by short-term dietary changes that can alter serum levels. However, assays for measuring RBC folate levels have also been fraught with unreliability. 3,31-33 It should be noted that low RBC folate levels have been reported with alcohol use, pregnancy and anticonvulsant medications. ${ }^{34}$ Another important cause of low RBC folate levels is vitamin B12 deficiency. ${ }^{29,30,35}$ It is estimated that approximately $60 \%$ of patients with pernicious anemia have low RBC folate levels, presumably because vitamin B12 is necessary for normal transfer of methyltetrahydrofolate from plasma to RBCs. ${ }^{28,36}$

\section{Methylmalonic Acid (MMA) and Homocysteine Serum Concentrations}

Cobalamin and folate are cofactors in several important metabolic pathways in the cell. The hydroxylated form of cobalamin plays an important role in the metabolism of homocysteine and MMA. The conversion of homocysteine to methionine requires both vitamin B12 and folate as cofactors. However, the metabolism of L-methylmalonyl CoA to succinyl CoA, an enzymatic pathway involved in oxidative phosphorylation reactions within the cell, only requires vitamin B12. These metabolites provide early information regarding the cellular state of vitamin B12 and folate and can be used to distinguish folate from vitamin B12 deficiency, since most patients with folate deficiency have normal MMA or mildly elevated levels. ${ }^{37-39}$ It should be kept in mind that nearly $50 \%$ of those with elevation of these metabolites will have normal serum vitamin B12 levels. ${ }^{1}$ This emphasizes the low sensitivity of using vitamin B12 levels, particularly in the presence of other signs or symptoms.

Previous studies on large groups of cobalamine and/or folate deficient patients have shown the ability of differentiating cobalamin deficiency from folate deficiency by measuring serum MMA and homocysteine levels. Both of these metabolites are elevated in cobalamin deficiency, with anemic cobalamin deficient patients showing marked elevations. However, MMA is more sensitive for identifying non-anemic cobalamin deficiency patients than homocysteine. In folate deficiency patients, serum homocysteine levels are markedly increased, while serum MMA levels are not elevated. ${ }^{40}$ Therefore, measuring the serum levels of these two metabolites not only helps in differentiating cobalamine deficiency from folate deficiency, but also provides a reliable degree of both sensitivity and specificity in diagnosing these important deficiency states. ${ }^{40}$ An important limitation that must be considered when measuring MMA is the presence of renal insufficiency, i.e., an elevated serum creatinine, and hypovolemia. Serum MMA will be elevated in patients with underlying renal dysfunction, decreasing its specificity and sensitivity in identifying patients with cobalamin deficiency. ${ }^{23}$ Similarly, hereditary homocysteinemia is a condition in which the serum homocysteine levels are elevated. Measurements of MMA levels are recommended when initial vitamin B12 and/or homocysteine levels are abnormal.

\section{Holotranscobalamin II (holoTC II)}

HoloTC II is an emerging marker that may be useful in establishing a diagnosis of early vitamin B12 deficiency in cases where there is a discordance between vitamin B12 levels and its metabolites, or in lieu of measuring vitamin B12, MMA 
and/or homocysteine concentrations. ${ }^{41}$ HoloTC II can also be used in cases of renal failure or myeloproliferative diseases in which vitamin B12 concentrations may be falsely elevated. ${ }^{23,42}$ HoloTC II is a metabolically active protein that transports cobalamin to cell membrane receptors. Its serum concentration can be used to measure the amount of vitamin B12 attached to the binding protein transcobalamin II. Compared to measurements of serum vitamin B12, holoTC II seems to have greater sensitivity and specificity. However, routine ordering of this test as part of the work-up to establish the diagnosis of vitamin B12 deficiency is not currently recommended. 43

There is currently no gold standard for diagnosing vitamin B12 deficiency. Until one is identified, it is recommended that when initial vitamin $\mathrm{B} 12$ values are low (i.e., $<150 \mathrm{ng} / \mathrm{L}$ ) and a vitamin B12 deficiency is suspected, the vitamin B12 level should be repeated on a separate occasion or tests should be used in combination (e.g., serum vitamin B12 level, MMA and homocysteine) ${ }^{25,44}$ Complete diagnostic testing should only be performed in cases of unexplained macrocytic anemia. 45

\section{Treatment of Vitamin B | 2 and Folate Deficiencies}

Traditionally, patients with vitamin B12 deficiency from any cause have received cyanocobalamin intramuscularly or subcutaneously $1000 \mu \mathrm{g} /$ week for 1 month and monthly, thereafter. This time-honored method remains an acceptable form of treatment for all causes of vitamin B12 deficiency, particularly when cognitive impairment or neurologic disease is present. Alternatively, hydroxocobalamin given in the same dose every 1-3 months intramuscularly is also effective therapy. This form of cobalamin remains in the tissues longer than the cyanocobalamin forms and can, therefore, be given less frequently. ${ }^{46}$ In cases of deficiency due to inadequate intake, food-cobalamin malabsorption and pernicious anemia, oral cyanocobalamin administered at 1000-2000 $\mu \mathrm{g}$ /day for 1 month, followed by $125-500 \mu \mathrm{g} /$ day is recommended and considered a safe and effective method of treatment. ${ }^{47}$ Other oral administration regimens have demonstrated efficacy and have proven to be equally as effective as intramuscular administration. ${ }^{48,49}$ In some cases, nasal or sublingual cyanocobalamin may also be useful in replenishing vitamin B12 stores. ${ }^{50}$ Because of the inherent unreliability of measuring either serum or $\mathrm{RBC}$ folate, it is recommended that patients receiving treatment for vitamin B12 deficiency receive empiric folate supplementation of $400 \mu \mathrm{g}$ /day to 1 $\mathrm{mg} /$ day. ${ }^{27,45,51}$ Maintenance therapy should continue until the underlying cause of the deficiency is corrected.

In folate deficiency, the serum folate level is very sensitive to dietary folate intake and responds well to short-term treatment. Long-term treatment is not warranted except with chronic conditions such as malnutrition, exfoliative dermatitis or hemolysis. ${ }^{52}$ A complete blood cell count 10-14 days after starting the treatment for vitamin B12 or folate deficiency should reveal a rise in hemoglobin and a decrease in MCV. A full hematologic response should occur within 8 weeks. During treatment, further monitoring of the complete blood cell count or measuring vitamin $\mathrm{B} 12$ and folate levels or their metabolites is not necessary. ${ }^{52}$ In patients taking long-term treatment for vitamin B12 deficiency, an annual complete blood cell count may be a reasonable consideration to monitor therapy.

\section{Acknowledgments}

The authors are grateful to Marian Menn and Veronica Tillema for providing the figures of macrocytosis in the peripheral blood smear. The authors thank Marshfield Clinic Research Foundation for its support through the assistance of Jennifer Hayes and Alice Stargardt in the preparation of this article.

\section{References}

1. Chanarin I, Metz J. Diagnosis of cobalamin deficiency: the old and new. Br J Haematol 1997;97:695-700.

2. Kasper DL, Braunwald E, Fauci A, Hauser S, Longo D, Jameson JL. Harrison's principles of internal medicine. $16^{\text {th }}$ ed. New York: McGraw-Hill Medical Publishing Division; 2005.

3. Davidson RJ, Hamilton PJ. High mean red cell volume: its incidence and significance in routine haematology. J Clin Pathol 1978;31:493-498.

4. Hattersley PG, Gerard PW, Caggiano V, Nash DR. Erroneous values on the Model S Coulter Counter due to high titer cold autoagglutinins. Am J Clin Pathol 1971;55:442-446.

5. Lindenbaum J. Status of laboratory testing in the diagnosis of megaloblastic anemia. Blood 1983;61:624-627.

6. Lawrence AC, Bevington JM, Young M. Storage of blood and the mean corpuscular volume. J Clin Pathol 1975;28:345-349.

7. Breedveld FC, Bieger R, van Wermeskerken RK. The clinical significance of macrocytosis. Acta Med Scand 1981;209:319-322.

8. Colon-Otero G, Menke D, Hook CC. A practical approach to the differential diagnosis and evaluation of the adult patient with macrocytic anemia. Med Clin North Am 1992;76:581-597.

9. Savage DG, Ogundipe A, Allen RH, Stabler SP, Lindenbaum J. Etiology and diagnostic evaluation of macrocytosis. Am J Med Sci 2000;319:343-352.

10. Hoffbrand AV, Pettit, JE. Clinical hematology: Sandoz atlas. London: Glower; 1988.

11. Nathan DG, Orkin SH, Look AT, Ginsburg D. Nathan and Oski's hematology of infancy and childhood. $6^{\text {th }}$ ed. Philadelphia: Saunders; 2003; 1841.

12. Hoffbrand V, Provan D. ABC of clinical haematology. Macrocytic anaemias. BMJ 1997;314:430-433.

13. Sechi LA, De Carli S, Catena C, Zingaro L, Bartoli E. Benign familial macrocytosis. Clin Lab Haematol 1996;18:41-43.

14. Thomas CW Jr, Lowry PW, Franklin CL, Weaver AL, Myhre GM, Mays DC, Tremaine WJ, Lipsky JJ, Sandborn WJ. Erythrocyte mean corpuscular volume as a surrogate marker for 6-thioguanine nucleotide concentration monitoring in patients with inflammatory bowel disease treated with azathioprine or 6-mercaptopurine. Inflamm Bowel Dis 2003;9:237-245.

15. Papadakis KA. Mean corpuscular volume: a simple and inexpensive way to monitor azathioprine/6-mercaptopurine treatment in patients with inflammatory bowel disease? Evidence-Based Gastroenterology 2004;5:22-23.

16. Petersen K, Hale BR, Wallace MR. Macrocytosis after nucleoside-containing HIV treatment regimens. Infect Dis Clin Pract 2005; 13:65-67.

17. Steele RH, Keogh GL, Quin J, Fernando SL, Stojkova V. Mean cell volume (MCV) changes in HIV-positive patients taking nucleoside reverse transcriptase inhibitors (NRTIs): a surrogate marker for adherence. Int J STD AIDS 2002;13:748-754. 
18. Bain BJ. Diagnosis from the blood smear. N Engl J Med 2005;353:498-507.

19. Torres Gomez A, Casano J, Sanchez J, Madrigal E, Blanco F, Alvarez MA. Utility of reticulocyte maturation parameters in the differential diagnosis of macrocytic anemias. Clin Lab Haematol 2003;25:283-288.

20. Hoffman R, Benz EJ Jr, Shattil SJ, Furie B, Cohen HJ, Silberstein LE, McGlave P, eds. Hematology: basic principles and practice. $4^{\text {th }}$ ed. New York, NY: Churchill Livingston; 2005.

21. Harris JW, Kellermeyer RW. The red cell. rev ed. Cambridge, MA: Harvard University Press; 1970. 387.

22. Hoffman R, Benz EJ Jr, Shattil SJ, Furie B, Cohen HJ, Silberstein LE, McGlave P, eds. Hematology: basic principles and practice. $2^{\text {nd }}$ ed. New York, NY: Churchill Livingston; 1995. 562-563.

23. Ward PC. Modern approaches to the investigation of vitamin B12 deficiency. Clin Lab Med 2002;22:435-445.

24. Snow CF. Laboratory diagnosis of vitamin B12 and folate deficiency: a guide for the primary care physician. Arch Intern Med 1999;159:1289-1298.

25. Andres E, Loukili NH, Noel E, Kaltenbach G, Abdelgheni MB, Perrin AE, Noblet-Dick M, Maloisel F, Schlienger JL, Blickle JF. Vitamin B12 (cobalamin) deficiency in elderly patients. CMAJ 2004;3:251-259.

26. Oh RC, Brown DL. Vitamin B12 deficiency. Am Fam Physician 2003;67:979-986.

27. Ashraf MJ, Goyal M, Hinchey K, Cook JR. Clinical utility of folic acid testing for anemia and dementia screen. J Gen Intern Med 2004;19(s1):130.

28. Chanarin I. The megaloblastic anaemias. $2^{\text {nd }}$ ed. Oxford, England: Blackwell Scientific Publishers; 1979.

29. Handin RI, Lux SE, Stossel TP. Blood: principles and practice of hematology. $1^{\text {st }}$ ed. Philadelphia, PA: Lippincott Williams \& Wilkins; 1995; 1406.

30. Handin RI, Lux SE, Stossel TP. Blood: principles and practice of hematology. $1^{\text {st }}$ ed. Philadelphia, PA: Lippincott Williams \& Wilkins; 1995; 1421.

31. Lindenbaum J, Allen RH. Clinical spectrum and diagnosis of folate deficiency. In: Bailey LB, ed. Folate in health and disease. New York, NY: Marcel Dekker; 1995. 43-73.

32. Antony AC. Megaloblastic anemias. In: Hoffman R, Benz EJ Jr, Shattil SJ, Furie B, Cohen HJ, Silberstein LE, McGlave P, eds. Hematology: basic principles and practice. $3^{\text {rd }}$ ed. New York, NY: Churchill Livingston; 2000. 446-485.

33. Jaffe JP, Schilling RF. Erythrocyte folate levels: a clinical study. Am J Hematol 1991;36:116-121.

34. Barney-Stallings RA, Heslop D. What is the clinical utility of obtaining a folate level in patients with macrocytosis or anemia? J Fam Pract 2001;50:544.

35. Lee GR, Foerster J, Lukens J, Paraskevas F, Greer JP, Rodgers GM, eds. Wintrobe's clinical hematology. $10^{\text {th }}$ ed. Baltimore: Williams \& Wilkins; 1999.

36. Tisman G, Herbert V. B12 dependence of cell uptake of serum folate: an explanation for high serum folate and cell folate depletion in B12 deficiency. Blood 1973;41:465-469.

37. Stabler SP, Marcell PD, Podell ER, Allen RH, Savage DG, Lindenbaum J. Elevation of total homocysteine in the serum of patients with cobalamin or folate deficiency detected by capillary gas chromatography-mass spectrometry. J Clin Invest 1988;81:466-474.

38. Allen RH, Stabler SP, Savage DG, Lindenbaum J. Diagnosis of cobalamin deficiency I: usefulness of serum methylmalonic acid and total homocysteine concentrations. Am J Hematol 1990;34:90-98.

39. Lindenbaum J, Savage DG, Stabler SP, Allen RH. Diagnosis of cobalamine deficiency: II. Relative sensitivities of serum cobalamine, methylmalonic acid, and total homocysteine concentrations. Am J Hematol 1990;34:99-107.
40. Savage DG, Lindenbaum J, Stabler SP, Allen RH. Sensitivity of serum methylmalonic acid and total homocysteine determinations for diagnosing cobalamin and folate deficiencies. Am J Med 1994;96:239-246.

41. Alpers DH. What is new in vitamin $\mathrm{B}(12)$ ? Curr Opin Gastroenterol 2005;21:183-186.

42. Lloyd-Wright Z, Hvas A, Moller J, Sanders TA, Nexo E. Holotranscobalamin as an indicator of dietary vitamin B12 deficiency. Clin Chem 2003;49:2076-2078.

43. Nilsson K, Isaksson A, Gustafson L, Hultberg B. Clinical utility of serum holotranscobalamin as a marker of cobalamin status in elderly patients with neuropsychiatric symptoms. Clin Chem Lab Med 2004;42:637-643.

44. Solomon LR. Cobalamin-responsive disorders in the ambulatory care setting: unreliability of cobalamin, methylmalonic acid, and homocysteine testing. Blood 2005;105:978-985.

45. Robinson AR, Mladenovic J. Lack of clinical utility of folate levels in the evaluation of macrocytosis or anemia. Am J Med 2001;110:88-90.

46. Shojania AM. Protein synthesis-megaloblastic disorders. In: Gross S, Roath S, eds. Hematology. A problem-oriented approach. Baltimore: Williams \& Wilkins. 1996. 25-54.

47. Nyholm E, Turpin P, Swain D, Cunningham B, Daly S, Nightingale P, Fegan C. Oral vitamin B12 can change our practice. Postgrad Med J 2003;79:218-220.

48. Bolaman Z, Kadikoylu G, Yukselen V, Yavasoglu I, Barutca S, Senturk T. Oral versus intramuscular cobalamin treatment in megaloblastic anemia: a single-center, prospective, randomized, open-label study. Clin Ther 2003;25:3124-3134.

49. Kuzminski AM, Del Giacco EJ, Allen RH, Stabler SP, Lindenbaum J. Effective treatment of cobalamin deficiency with oral cobalamin. Blood 1998;92:1191-1198.

50. Sharabi A, Cohen E, Sulkes J, Garty M. Replacement therapy for vitamin B12 deficiency: comparison between the sublingual and oral route. Br J Clin Pharmacol 2003;56:635-638.

51. Latif T, Hsi ED, Rybicki LA, Adelstein DJ. Is there a role for folate determinations in current clinical practice in the USA? Clin Lab Haematol 2004;26:379-383.

52. Smellie WS, Wilson D, McNulty CA, Galloway MJ, Spickett GA, Finnigan DI, Bareford DA, Greig MA, Richards J. Best practice in primary care pathology: review 1 . J Clin Pathol 2005;58:1016-1024.

\section{Author Affiliations}

Florence Aslinia, MD, Department of Internal Medicine, Marshfield Clinic, 1000 N. Oak Avenue, Marshfield,

Wisconsin 54449.

Joseph J Mazza, MD, MACP, Department of Hematology/Oncology, Marshfield Clinic, 1000 N. Oak Avenue, Marshfield, Wisconsin 54449.

Steven H. Yale, MD, FACP, Department of Internal Medicine, Marshfield Clinic and Clinical Research Center, Marshfield Clinic Research Foundation, 1000 N. Oak Avenue, Marshfield, Wisconsin 54449. 